\title{
Projection of drought-inducing climate conditions in the Czech Republic according to Euro-CORDEX models
}

\author{
Petr Štěpánek ${ }^{1,2, *}$, Pavel Zahradníček ${ }^{1,2}$, Aleš Farda ${ }^{1}$, Petr Skalák $^{1,2}$, \\ Miroslav Trnka ${ }^{1,3}$, Jan Meitner ${ }^{1}$, Kamil Rajdl ${ }^{1}$ \\ ${ }^{1}$ Global Change Research Institute CAS, Belidla 986/4a, Brno 60300, Czech Republic \\ ${ }^{2}$ Czech Hydrometeorological Institute, Na Šabatce 2050/17, Praha 14306, Czech Republic \\ ${ }^{3}$ Institute of Agriculture Systems and Bioclimatology, Mendel University in Brno, Zemedelska 1, 613 00 Brno, Czech Republic
}

\begin{abstract}
The end of the 20th century and the beginning of the 21st century in the Czech Republic were characterized by frequent extreme water cycle fluctuations, i.e. the occurrence of increased incidences of flood and drought events. Drought occurs irregularly in the Czech Republic during periods with low precipitation amounts. The most noteworthy droughts with significant impact, especially to agriculture, occurred in the years 2000, 2003, 2007, 2009, 2012, 2014 and 2015. A significant increase in frequency and length of drought periods was detected in future climate projections based on the latest model outputs, such as from the Euro-CORDEX $0.11^{\circ}$ resolutions for the European area. For these model experiments, the following greenhouse gas emissions scenarios were used: Representative Concentration Pathway (RCP) 4.5 (milder scenario) and RCP8.5 (pessimistic scenario). Since the climate models suffer from potentially severe biases, it is necessary to statistically correct their outputs. For this purpose, a suitable reference dataset was prepared, based on quality-controlled, homogenized and gap-filled station time series. The correction method applied was based on variable correction using individual percentiles. From the corrected model outputs, selected extreme indexes with respect to drought analysis were calculated. From the results, it follows that we can expect both an increase in air temperature and in precipitation (with increased amounts per event), as well as an increase in other extremes with the capability of inducing drought (number of tropical days, heat waves, etc.).
\end{abstract}

KEY WORDS: Euro-CORDEX simulations $\cdot$ Model bias correction $\cdot$ Climate change $\cdot$ Drought indices $\cdot$ Czech Republic

\section{INTRODUCTION}

As is shown in several studies in this CR Special, drought constitutes a potential threat to people's livelihoods and socioeconomic development, including in the Central European region (e.g. Brázdil et al. 2016, this issue). Compared to hazards such as floods, drought tends to occur less frequently. However, when it does occur, it generally affects a broad region for seasons or years at a time (UNISDR 2009). Drought originates from a deficiency of precipitation over an

${ }^{*}$ Corresponding author: stepanek.p@czechglobe.cz extended period of time, usually a season or more. This deficiency can result in water shortage for some activities, groups or environmental sectors. Drought is different from other hazards in that it develops slowly, sometimes over years, and its onset can be masked by a number of factors. Drought is an issue concerning all European Union (EU) countries. According to Spinioni et al. (2016) the drought episodes affected, on average, $15 \%$ of the EU territory and $17 \%$ of the EU population from 2006 to 2010. This caused considerable damages and economic losses that were esti-

() The authors 2016. Open Access under Creative Commons by Attribution Licence. Use, distribution and reproduction are unrestricted. Authors and original publication must be credited. 
mated at over $€ 100$ billion (e.g. Spinioni et al. 2016). Water shortage in Europe is a serious problem in many regions (Vogt \& Somma 2013), and estimates for the 21st century show an increasing chance of drought across most of the European continent (Stocker et al. 2013). However, the character of these changes is important for adaptation options. For instance, for a number of catchments in Central Europe, the projected average annual changes in water level are relatively small, despite considerable changes in seasonal distribution, even for high-impact scenarios (e.g. Hanel et al. 2012, 2013). This suggests that the development of accumulation capacities might be an adaptation option. However, if the periods of drought cover multiple years, this adaptation option may no longer be efficient. As another example, the timing of drought onset and the maximum deficit is important for the impacts on agricultural production. In the studied region, more crops and larger areas are vulnerable to drought in the first half of the growing season (especially April-June) than in July-September, with the notable exception of maize, potatoes and sugar beet (Hlavinka et al. 2009). The year-to-year variability of drought can be related to circulation patterns, as shown e.g. by Trnka et al. (2009) and Kingston et al. (2015). There is evidence that the trends in soil moisture anomalies in Central Europe are indeed linked to the occurrence of atmospheric circulation patterns that are conducive to drought. It also appears that long-term trends in the frequency of drought-conducive circulation patterns have contributed to a change in the duration and intensity of drought episodes (Trnka et al. 2009). This phenomenon is particularly pronounced during the early vegetation period (April-June), which is crucial both for the productivity of managed ecosystems (e.g. rain-fed field crops) as well as for the net primary production of central European ecosystems as a whole. Recent studies have introduced evidence of decreasing soil moisture content since 1961 (Trnka et al. 2015), and attributed it to increasing $\mathrm{CO}_{2}$ levels related to anthropogenic forcing (Brázdil et al. 2015).

High-resolution information about future climate is needed for proper adaptation and mitigation of the impacts of climate change and variability. Driven by a suite of IPCC assessment reports and accompanied by increasing public awareness of ongoing climate change, the past decades have seen rapid development in the corresponding methods for climate scenario generation (Kotlarski et al. 2014). The primary tools used for this task are climate models. Unfortunately, high-resolution climate simulations are still not computationally affordable with global climate models (GCMs). A coarse resolution also precludes global models from providing an accurate description of extreme events, which are of fundamental importance to users of climate information with respect to the regional and local impacts of climate variability and change (Giorgi et al. 2009). To obtain climate change information at the regional to local scale, different downscaling techniques are applied on GCMs' outputs. Dynamical downscaling (Giorgi \& Mearns 1991) using a regional climate model (RCM) is an example of such a technique.

RCMs (Giorgi \& Mearns 1999, Wang et al. 2004) are widely used tools for providing regional climate information over limited areas. The availability and reliability of RCM simulations for Europe has increased rapidly in recent years, thanks to projects such as PRUDENCE (Christensen \& Christensen 2007), STARDEX (Goodess et al. 2012), ENSEMBLES (van der Linden \& Mitchell 2009), and recently, NARCCAP (Mearns et al. 2012) and CORDEX (Giorgi et al. 2009). However, RCMs feature considerable systematic errors (see e.g. Frei et al. 2003, Suklitsch et al. 2010), which hampers easy application of RCM results in climate change impact research.

Since model outputs suffer from systematic errors (due to a necessary simplification of complex realworld processes: coarser spatial resolution, parameterizations, etc.), it is necessary to correct them to obtain meaningful results on the simulated properties of the climate system. Generally, when dealing with mean values of meteorological elements (e.g. seasonal and annual values), the changes given by the models can be treated as they are, without any modifications. The problem occurs in the analysis of daily data and extreme values (such as temperature maxima and minima, precipitation values over given thresholds, etc.), where incorrect statistical distribution simulated by a model (in particular withregards to its tail parts) for a given meteorological element may lead to incorrect conclusions. To cope with distorted statistical moments of different order, different model correcting techniques are applied (a list of these is given in e.g. Themessl et al. 2012). In the present work, the model outputs were corrected using our own correction method (distribution adjusting by percentiles, or DAP) that is based on the quantile mapping (QM) approach of Déqué (2007) (see details in Section 2.3).

Our previous analyses of climate change for the Czech Republic (Štěpánek et al. 2012, Brázdil \& Trnka 2015) were based only on the Special Report on Emissions Scenarios (SRES) emissions scenario A1B and 2 models, ALADIN-Climate/CZ, either in 25 or $10 \mathrm{~km}$ resolution (Farda et al. 2010), or RegCM (Pal 
et al. 2007). Here we present new results based on an ensemble of 11 simulations of Euro-CORDEX RCMs (described in Section 2.2). Euro-CORDEX simulations are based on Representative Concentration Pathway (RCP) scenarios (Moss et al. 2008). These scenarios take radiative forcing $\left(\mathrm{W} \mathrm{m}^{-2}\right)$ as the characteristic driving variable, instead of the concentration of the equivalent $\mathrm{CO}_{2}$ (ppm). The RCPs are consistent with a wide range of possible changes in future anthropogenic greenhouse gas emissions. RCP2.6 assumes that global annual greenhouse gas emissions will peak around 2010-2020, with emissions declining thereafter. Emissions in RCP4.5 are expected to peak around 2040, and then decline. In RCP6 (not used in the present study), emissions peak around 2080; in RCP8.5, emissions continue to rise throughout the 21st century (Meinshausen et al. 2011). The differences between the older results (based on SRES scenarios) and these new results are discussed in Section 4.

Since the volume of obtained results is enormous and there is not enough space in this article to show them all, only selected features of a combination of all 11 experiments for the whole Czech Republic (spatial aggregates) will be presented here (in Section 3). Nonetheless, the obtained material will serve for further analysis and be published on the web portal designated for the exchange of information on climate change impacts, vulnerability and adaptation measures on the territory of the Czech Republic (www.klimatickazmena.cz/en/).

\section{METHODS}

\subsection{Station data}

For proper validation of the RCM outputs and their later correction, station data of the highest quality has to be used. First, the underlying raw station data should be subject to thorough quality control. Data quality control applicable to large datasets was developed by Štěpánek et al. (2009). Automation of the process (preserving a good ratio of true and false alarms) was achieved through a combination of several methods of temporal and spatial analysis.

Once the erroneous data are removed from the series during quality control, the series are the subject of homogenization, applying several statistical tests for the detection of inhomogeneities, and found discontinuities are corrected in the daily scale (again, several methods are applied to decrease the uncertainty of the correction estimates). Further details on the homogenization can be found in e.g. Štěpánek et al. (2013) or in the documentation of the software (Štěpánek 2010). Quality control and correction of inhomogeneities were performed on a daily (subdaily) basis for all key meteorological variables (air temperature, precipitation, sunshine duration, relative humidity, wind speed) over the territory of the Czech Republic since 1961 (as well as for neighboring countries, such as the Slovak Republic and Austria, within international projects).

After quality control and homogenization, missing values were filled in. Calculation of the 'new' values was based on geostatistical interpolation methods, improved by standardization of neighboring stations' values to the altitude of a given location by means of regional regression analysis (Štěpánek et al. 2011). Parameter settings of the calculation differ for each meteorological element, and the optimal settings were found by means of cross-validation.

Data quality control, homogenization and the filling in of missing values led to the creation of a socalled 'technical' series for mean, maximum and minimum temperatures, precipitation totals, sums of sunshine duration, relative humidity (mean water vapor pressure) and wind speed. These were calculated for 268 climatological and 787 rain-gauge stations of the Czech Hydrometeorological Institute (CHMI) network in the 1961-2009 period, and actual values are continually being added. Despite the fact that a smaller number of stations was available for some of the studied characteristics (e.g. for sunshine duration or water vapor pressure), the 'technical' series were completely calculated (both for arbitrary station location and regular gridded network). In this way, we have a complex set of meteorological variables for each position of a climatological station, which could easily be applied in any climate analysis or impact study in this territory.

\subsection{Model simulations}

Our analysis of future climate conditions is based on RCM simulations prepared within the European part of the global Coordinated Regional Climate Downscaling Experiment (CORDEX, www.cordex. org). CORDEX is an international effort supported by the World Climate Research Programme (WRCP), aimed at producing a set of climate change projections covering individual world regions with multiple RCMs and several emissions scenarios. Thus, the climate research community gets more reliable information on future climate parameters, including information on related uncertainty. To account for 
greenhouse gases and aerosol forcing, RCP scenarios are used (van Vuuren et al. 2011). The GCM output from the Coupled Model Intercomparison Project Phase 5 (CMIP5; Taylor et al. 2012) has been utilized as the source of driving data for the RCMs. Generally, CORDEX models follow a unified model setup, including control, historic (hindcast) and future climate projection experiments.

The European domain of CORDEX is covered within the frame of the Euro-CORDEX sub-project (www.eurocordex.net). Model experiments are performed here in 2 spatial resolutions:

$0.44^{\circ}$ and $0.11^{\circ}$. In total, 10 different RCMs and 13 driving GCMs have been employed. In our paper, we focus only on the $0.11^{\circ}$ resolution experiments forced by the RCP2.6 (van Vuuren et al. 2007), RCP4.5 (Clarke et al. 2007) and RCP8.5 (Riahi et al. 2007) scenarios, respectively. The following RCMs were used in our study: ALADIN53, CCLM4-8-17, HIRHAM5, RACMO22E and RCA4. Two of the 5 RCMs were driven by $>1$ GCM. The selection of the experiments was based on their availability in July 2015, and is summarized in Table 1. Also included in Table 1 is the identification code of the particular simulation (e.g. r1i1p1) taken from the CMIP5 GCM ensemble to drive an RCM.

\subsection{RCM bias correction}

The climate simulated by numerical models shows systematic deviations from reality (true observed climate), which limits their applicability for impact models. Therefore, climate model outputs have to be post-processed to match the observed climate (Christensen et al. 2008, Maraun 2013). One common way of dealing with model errors in climate change impact studies is the delta change approach (Räty et al. 2014). Besides the delta approach, more sophisticated RCM post-processing methods have been proposed and evaluated, and their list is given in e.g. Themessl et al. (2012). These approaches belong to the family of model output statistics (MOS), a concept developed in weather forecasting and now commonly used in climate science (Maraun et al. 2010).

In a comprehensive intercomparison study of $7 \mathrm{em}$ pirical-statistical downscaling and error correction methods (DECMs) for daily precipitation from a $10 \mathrm{~km}$ resolved RCM, Themessl et al. (2011) conclude that QM outperforms all other investigated DECMs. In ad- dition, they also show — at least for daily precipitation linear regression approaches, although optimized by predictor transformation and randomization-that RCM error characteristics are not systematically reduced by these methods. The distribution mapping method was recommended as the best-performing correction method by Teutschbein \& Seibert (2013), where various bias correction techniques were compared (delta change correction, linear transformation, local intensity scaling $[\mathrm{LOCI}]$, power transformation, variance scaling, distribution mapping), finding that QM was best able to cope with non-stationary conditions.

Based on the those results, QM was chosen for the bias correction purposes in the present work. Our method originates from an approach described in e.g. Déqué (2007). It is applied as parameter-free (using empirical cumulative density distributions, rather than theoretical cumulative distribution functions). An empirical method is recommended over the parametric one, since the latter is not robust enough, given the limited length of the time period (Gutjahr \& Heinemann 2013), and also, using theoretical distribution, QM becomes less flexible in its application to different parameters and regions as a priori information about the shape of the probability density functions is needed (Themessl et al. 2012).

Based on validation of the QM method within model control runs, we further adopted some settings that best suit the purpose of bias correction of various meteorological elements (including precipitation, which is difficult to handle on both distribution tails). For example, the final corrections (obtained for individual percentiles) were smoothed with a lowpass Gaussian filter (over 20 percentiles) to reduce noise in the individual percentile values. Each month was treated separately and a time window including the previous and following month was applied: thus, 
Table 2. Model bias for air temperature $\left({ }^{\circ} \mathrm{C}\right.$ ) as difference between original (uncorrected) model and reality, areal averages for different altitudes

\begin{tabular}{|lccccc|}
\hline Altitude $(\mathrm{m})$ & $\begin{array}{c}\text { CNRM-CM5_ } \\
\text { ALADIN }\end{array}$ & $\begin{array}{c}\text { EC-EARTH_R } \\
\text { ACMO }\end{array}$ & $\begin{array}{c}\text { EC-EARTH_ } \\
\text { RCA }\end{array}$ & $\begin{array}{c}\text { HadGEM2-ES_ } \\
\text { RCA }\end{array}$ & $\begin{array}{c}\text { MPI-ESM-LR_ } \\
\text { CCLM }\end{array}$ \\
\hline $0-300$ & -2 & -2.46 & -1.81 & -0.3 & -0.7 \\
$300-600$ & -1.92 & -2.21 & -1.76 & -0.24 & -0.66 \\
$600-900$ & -1.39 & -1.92 & -1.6 & -0.06 & -0.43 \\
$900-1200$ & -0.51 & -1.42 & -1.19 & 0.34 & 0.18 \\
Above 1200 & 0.37 & -0.4 & -0.32 & -0.23 & -0.62 \\
Whole Czech Republic & -1.83 & -2.21 & -1.74 & -0.21 & - \\
\hline
\end{tabular}

we get rid of the steps between the individual months and at the same time comply with different bias sizes in different parts of a year. To preserve reasonable extrapolated values (in the tails of the distribution), changes between individual values of the highest (or lowest) percentiles (likely to be very noisy) were limited to certain values (such as a coefficient of 1.5 for maximal extrapolated value compared to the last percentile, and a ratio of 3.0 as a change between the last percentiles values).

The QM method was applied on a daily basis and for each grid cell/location separately. To be suitable for impact studies where station data are preferred (and because these data are also available for the current climate), the correction/localization was done by finding the nearest grid points for a given location (station) and applying the correction several times, 5 times in the case of precipitation to 10 times in the case of other elements. In practice, the first (nearest) neighbor was applied as the final correction, but the other results were used to evaluate uncertainty coming from the correction process.

We call this correction method DAP (distribution adjusting by percentiles), simply to distinguish it from other QM methods, since it differs by the abovementioned parameters settings. For the data processing, the software packages AnClim (Štěpánek 2008), LoadData and ProClimDB (Štěpánek 2010) were created. They offer a complex solution, from tools for handling databases, through data quality control, to homogenization of time series, as well as time series analyses, extreme value evaluation and model output verification and correction. The software is available on the webpage www.climahom.eu.

\section{RESULTS}

\subsection{Bias in model data}

Over the Czech Republic, we found bias patterns similar to those discussed in Kotlarski et al. (2014) and briefly described in Section 4 (the present study). In this subsection we summarize our main findings for some of the meteorological variables influencing evapotranspiration and drought occurrence.

Biases between projection and reality were analyzed, in detail, mainly for 5 selected experiments. A control run was compared with the real meteorological data. For spatial comparison, individual maps with values interpolated into $500 \mathrm{~m}$ resolution were obtained for each data source (stations or model grid points).

Air temperature is underestimated by uncorrected models (Table 2). The greatest differences were observed for the experiment EC-EARTH_RACMO for which the average annual temperature is about $2.2^{\circ} \mathrm{C}$ lower than reality. In spring, it is underestimated by about $4^{\circ} \mathrm{C}$. The lowest biases were achieved by HadGEM2-ES_RCA, where the difference from reality is only $-0.2^{\circ} \mathrm{C}$. Overall, for all 5 selected experiments, the worst results were found in the spring season (Fig. 1).

A bias analysis was also performed in regard to different altitudes (since model orography differs from actual orography). We chose 5 levels: up to $300 \mathrm{~m}$, 301-600 m, 601-900 m, 901-1200 m and >1200 m. The results are surprising. The highest model biases are observed within the lower altitudes (up to $300 \mathrm{~m}$ ); in contrast, the model simulations for mountain regions are relatively non-biased. Two of the experiments are different, HadGEM2-ES_RCA and MPIESM-LR_CCLM, which have quite accurate results. These 2 experiments did, however, overestimate the temperature in the highest mountains (Fig. 2).

For a selected experiment (EC-EARTH_RACMO22, whose values are, after bias correction, in the middle of a value spread of other models), we tested whether the bias is constant or changes over time. Spatial biases for different decades of the control run are shown in Fig. S1 (in the Supplement at www.int-res.com/ articles/suppl/c070p179_supp.pdf). The biggest underestimation is observed in the case of older values (first decades of the control run period). A bias of about 

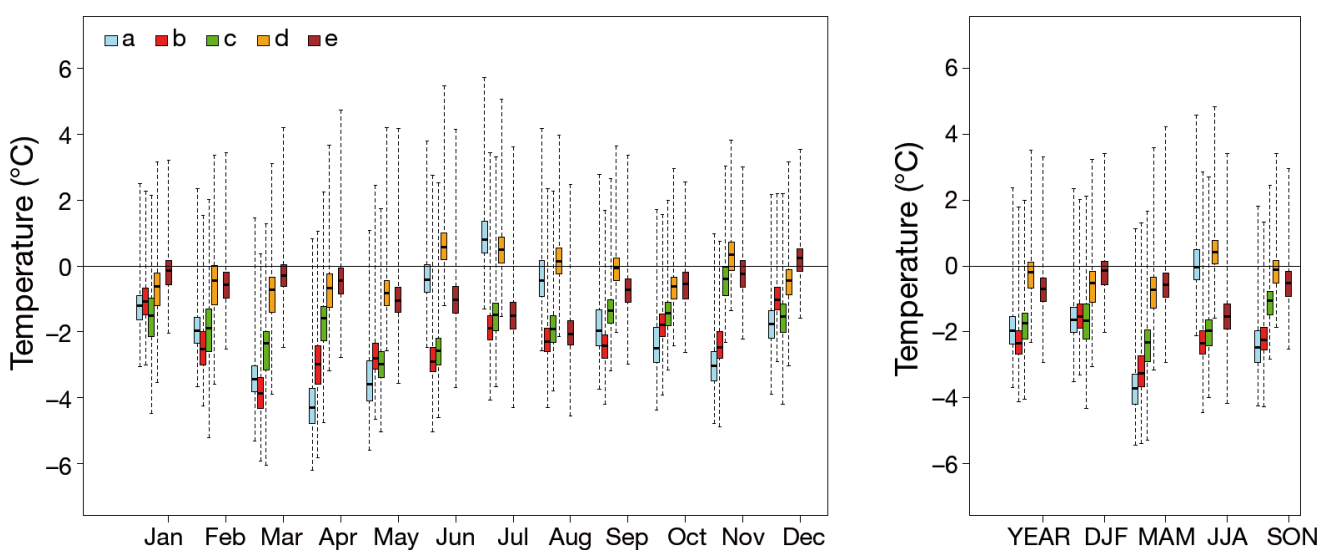

Fig. 1. Temperature bias, difference between original (uncorrected) model and reality, for 5 experiments, by month (left panel) and by season (right panel): (a) CNRM-CM5_ALADIN (1961-2005), (b) EC-EARTH_RACMO (1961-2005), (c) ECEARTH_RCA (1970-2005), (d) HadGEM2-ES_RCA (1970-2005), (e) MPI-ESM-LR_CCLM (1961-2005). Boxplots-central line: median; box: interquartile range (IQR); whiskers: outlier limits $(1.5 \times$ the IQR)

$-2.5^{\circ} \mathrm{C}$ is found for the period 1961-1970 (Table 3), while a bias of only $-2^{\circ} \mathrm{C}$ is found in the last years of the control run (1991-2005). This means that the modeled air temperature increase in the current climate is more rapid than it is in reality.

Precipitation sums are overestimated by the uncorrected model outputs (Fig. 3). From the 5 selected experiments, the wettest conditions are modeled by MPI-ESM-LR_CCLM; its average daily precipitation is higher by about $0.65 \mathrm{~mm}$ (Table 4). In contrast, almost bias-free precipitations are simulated by the ECEARTH_RACMO experiment. The remaining 3 models overestimated the precipitation by about $0.35 \mathrm{~mm}$ $\mathrm{d}^{-1}$. Spring is wetter compared to the other seasons.

More precipitation is simulated for the Bohemia (west) region than for Moravia (east) (Fig. 4). Spatial differences of biases by altitude are not as evident as in the case of the air temperature. The precipitation sums in lowlands are overestimated, especially by the CNRM-CM5_ALADIN and MPI-ESM-LR_CCLM experiments (Table 4). Mountain regions are modeled with a higher amount of precipitation in the case of the EC-EARTH_RCA and HadGEM2-ES_RCA experiments. In contrast, the EC-EARTH_RACMO experiment predicts lower precipitation sums than the reality for altitudes above $600 \mathrm{~m}$.

Table 3. Model bias for air temperature $\left({ }^{\circ} \mathrm{C}\right)$ as difference between original (uncorrected) EC-EARTH_RACMO22 and reality, areal averages for the Czech Republic

\begin{tabular}{|lccc|}
\hline Period & Average & Minimum & Maximum \\
\hline $1961-1970$ & -2.46 & -4.18 & 0.38 \\
$1971-1980$ & -2.27 & -4.11 & 0.66 \\
$1981-1990$ & -2.1 & -3.89 & 0.84 \\
$1991-2000$ & -2.09 & -3.8 & 0.97 \\
$2001-2005$ & -1.9 & -3.69 & 1.28 \\
\hline
\end{tabular}
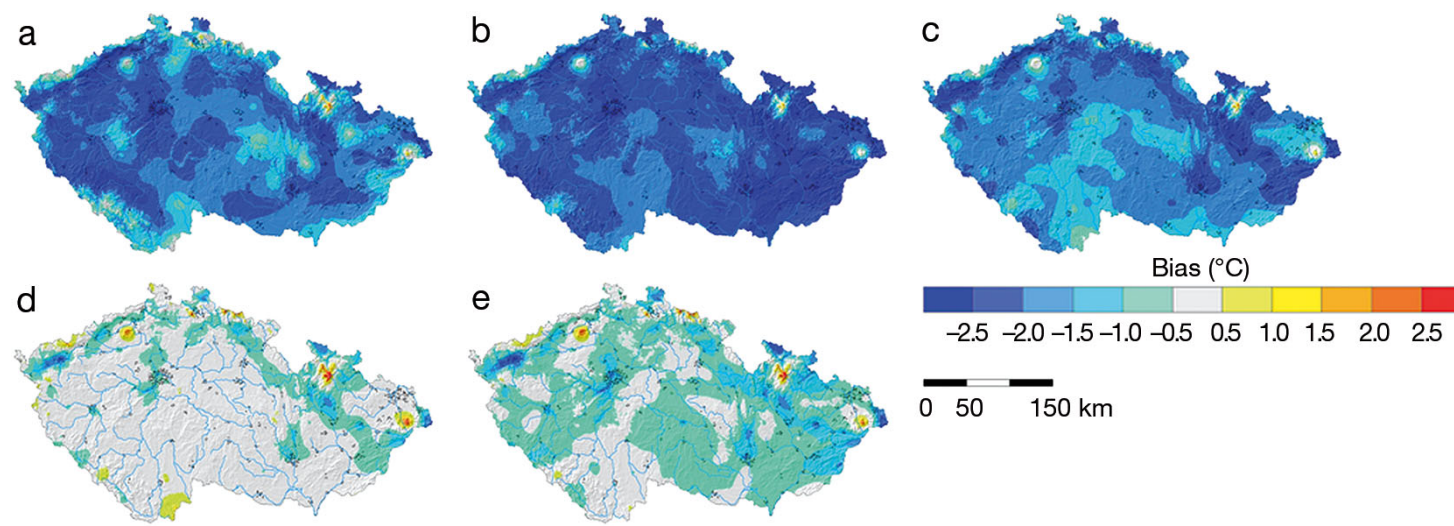

$\overline{0} 5 \overline{150} \mathrm{~km}$

Fig. 2. Temperature spatial bias for 5 experiments across the Czech Republic: (a) CNRM-CM5_ALADIN (1961-2005), (b) ECEARTH_RACMO (1961-2005), (c) EC-EARTH_RCA (1970-2005), (d) HadGEM2-ES_RCA (1970-2005), (e) MPI-ESMLR_CCLM (1961-2005) 

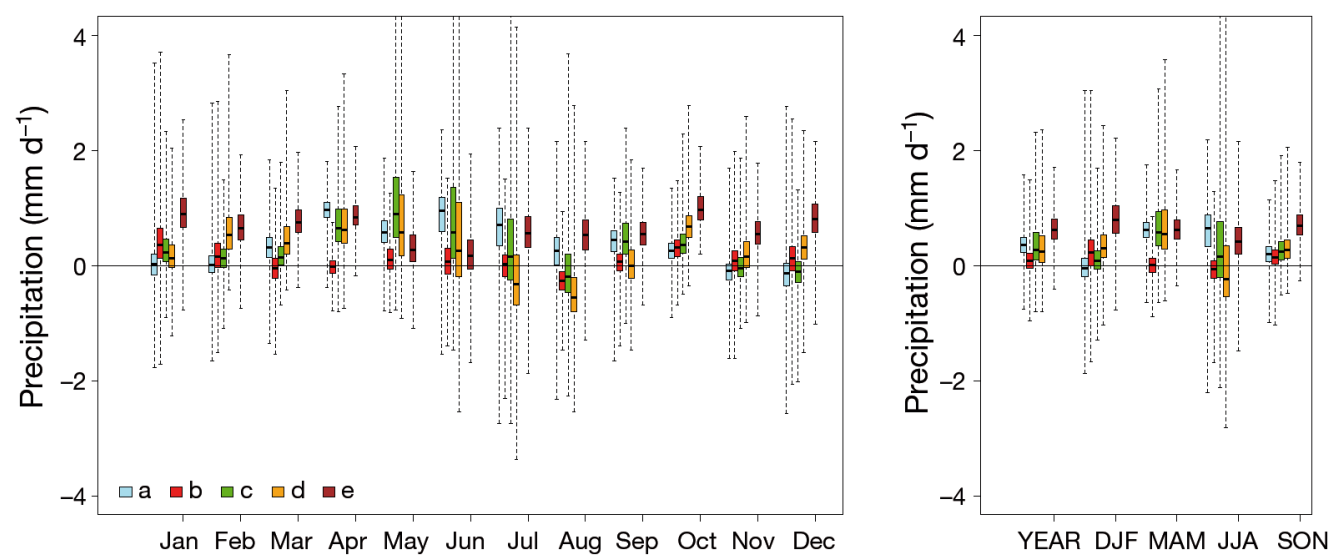

Fig. 3. Precipitation bias, difference of original (uncorrected) model and reality, for 5 experiments, by month (left panel) and by season (right panel): (a) CNRM-CM5_ALADIN (1961-2005), (b) EC-EARTH_RACMO (1961-2005), (c) EC-EARTH_RCA (1970-2005), (d) HadGEM2-ES_RCA (1970-2005), (e) MPI-ESM-LR_CCLM (1961-2005). Boxplots - central line: median; box: interquartile range (IQR); whiskers: outlier limits $(1.5 \times$ the IQR)

The number of days with precipitation $\geq 1 \mathrm{~mm}$ are overestimated by RCMs (Fig. 5, left), the same as with precipitation sums. The overestimation ends with number of days with $\geq 10 \mathrm{~mm}$ (with underestimation for JJA and overestimation for MAM). For $20 \mathrm{~mm}$, JJA and DJF are underestimated (resulting in the whole year being underestimated). For $50 \mathrm{~mm}$, all seasons are underestimated (more JJA and DJF). Some examples are given in the Section 3.2.

The initially large differences among the individual experiments (as seen e.g. on Fig. 5) become more consistent after the bias correction. From this, we can conclude that for impact studies in which absolute values play an important role (compared to climatological analysis, which are usually based only on value changes between various periods), bias correction is necessary to obtain meaningful results comparable with the current station (baseline) period.

\subsection{Future climate for the Czech Republic}

We analyse future climate in this study based on bias-corrected data. To comprehensibly estimate change in climate for the whole area of the Czech Republic, simple means over all possible grid points were calculated (in the Discussion section, we give information about comparison of various ways of areal averaging). For time series analysis, the values of the individual experiments were smoothed with a 10 yr low-pass Gaussian filter to get rid of incomparable individual yearly values. To better assess possible change based on all the available experiments, an ensemble mean was created from the individual corrected model outputs (see Figs. S2 \& S3 in the Supplement), and is further used in this study.

Based on all available experiments, air temperature in the Czech Republic will increase by $2.0^{\circ} \mathrm{C}$ annually by the end of the 21st century using RCP4.5, or by $4.1^{\circ} \mathrm{C}$ in the case of the RCP8.5 scenario compared to the reference period (1981-2010). As can be seen in Fig. S2 (in the Supplement), the air temperature will increase similarly to the year 2050 irrespective of the emissions scenarios. The temperature will be about $1^{\circ} \mathrm{C}$ higher in the period 2021-2040 compared to 1981-2010. We see growing differences between emissions scenarios after the year 2050. Temperatures predicted by RCP8.5 rise steeply, and,

Table 4. Model bias for precipitation $\left(\mathrm{mm} \mathrm{d}^{-1}\right)$ as difference between original (uncorrected) model and reality, areal averages for different altitudes

\begin{tabular}{|lccccc|}
\hline Altitude $(\mathrm{m})$ & $\begin{array}{c}\text { CNRM-CM5 } \\
\text { ALADIN }\end{array}$ & $\begin{array}{c}\text { EC-EARTH_ } \\
\text { RACMO }\end{array}$ & $\begin{array}{c}\text { EC-EARTH_ } \\
\text { RCA }\end{array}$ & $\begin{array}{c}\text { HadGEM2-ES_ } \\
\text { RCA }\end{array}$ & $\begin{array}{c}\text { MPI-ESM-LR_ } \\
\text { CCLM }\end{array}$ \\
\hline $0-300$ & 0.41 & 0.11 & 0.18 & 0.12 & 0.51 \\
$300-600$ & 0.36 & 0.07 & 0.33 & 0.29 & 0.68 \\
$600-900$ & 0.22 & -0.01 & 0.68 & 0.97 & 0.78 \\
$900-1200$ & 0 & -0.25 & 0.97 & 0.98 & 0.66 \\
Above 1200 & -0.1 & -0.48 & 0.98 & 0.32 & 0.65 \\
Whole Czech Republic & 0.34 & 0.06 & 0.36 & & \\
\hline
\end{tabular}



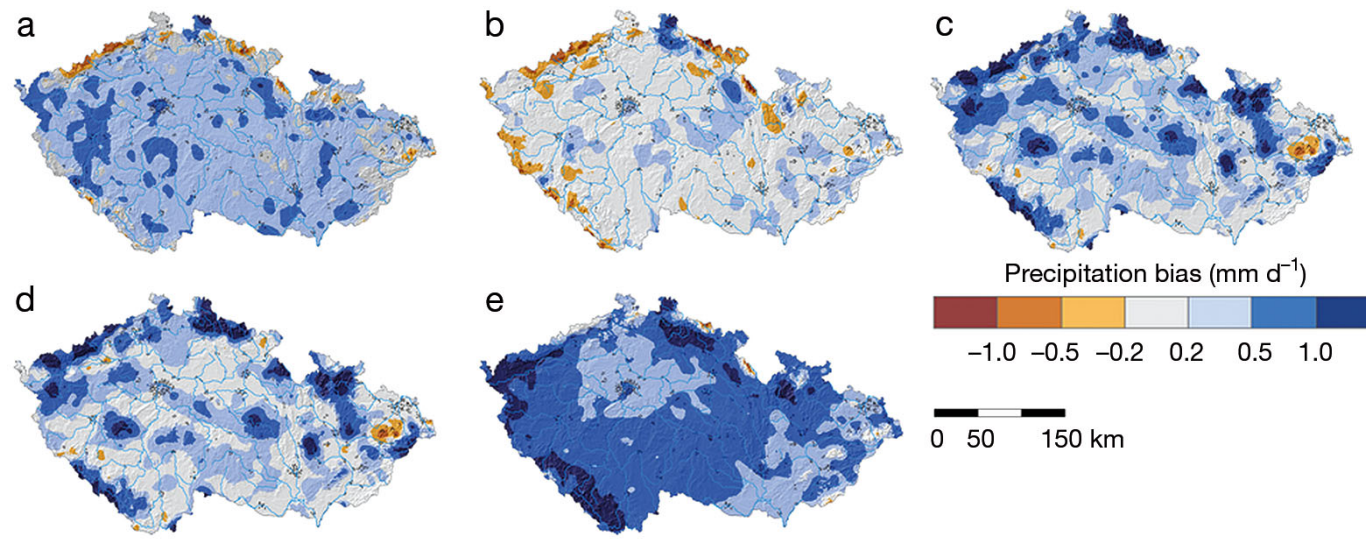

Fig. 4. Precipitation spatial bias for 5 experiments across the Czech Republic: (a) CNRM-CM5_ALADIN (1961-2005), (b) ECEARTH_RACMO (1961-2005), (c) EC-EARTH_RCA (1970-2005), (d) HadGEM2-ES_RCA (1970-2005), (e) MPI-ESMLR_CCLM (1961-2005)

for example, the HadGEM2-ES_RCA experiment (having one of the highest trend values) gives, by the end of this century, climate warming of about $5^{\circ} \mathrm{C}$ compared with the reference period 1981-2010 (Fig. S4 in the Supplement). In contrast, RCP4.5 maintains a practically stable climate from 2061, with a temperature higher by about $2^{\circ} \mathrm{C}$ compared to the present. According to RCP2.6, the trend will even become negative (and still statistically significant, $\mathrm{p}=$ 0.05 ) by the end of the 21st century. Of the individual seasons, the highest increase in air temperature is modeled for winter. By the end of the 21st century, winter temperature should be higher by about $4.9^{\circ} \mathrm{C}$ (RCP8.5) (Table 5).

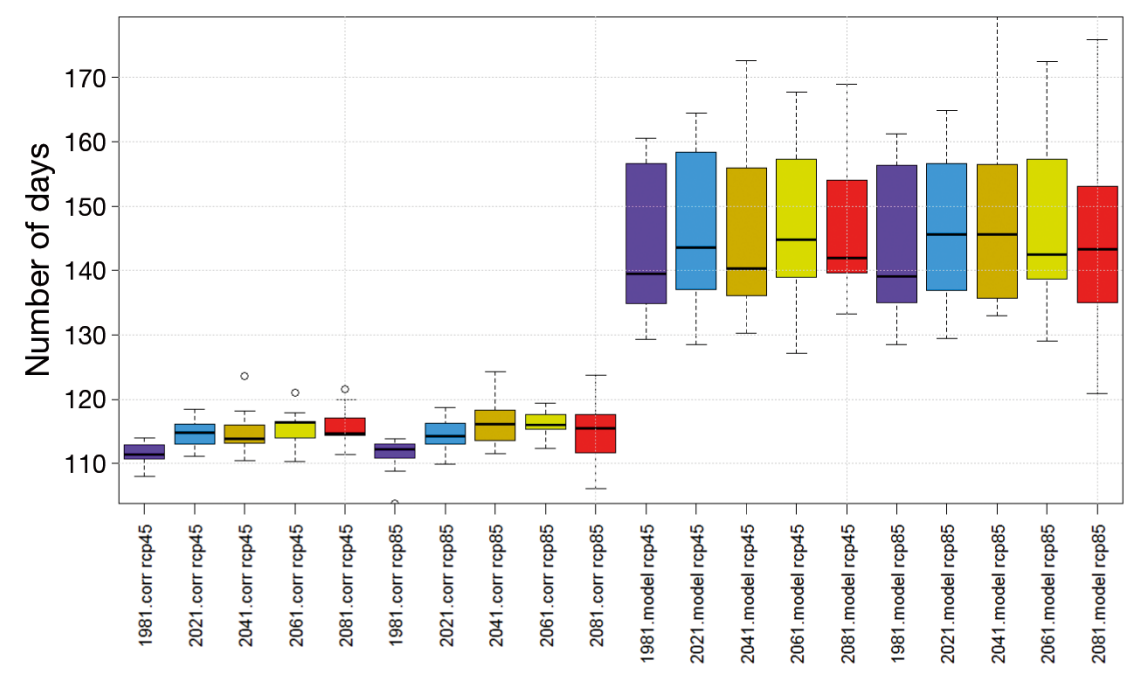

Fig. 5. Boxplots over all 11 experiments for number of days with precipitation $\geq 1.0 \mathrm{~mm}$ (corr: bias-corrected model outputs; model: original model values), for $30 \mathrm{yr}$ (1981-2010) and future $20 \mathrm{yr}$ periods (beginning of periods given on $x$-axis), and 2 scenarios: RCP4.5 and RCP8.5. Boxplots - central line: median; box: interquartile range $(\mathrm{IQR})$; whiskers: outlier limits $(1.5 \times$ the IQR); small circles: outlier values (values beyond the outliers limit). Colours show different decades
Maximum temperature is to increase mainly in winter, and the least in spring. Absolute maxima reach values of $2.3^{\circ} \mathrm{C}$ for the year and $3.4^{\circ} \mathrm{C}$ for winter (RCP4.5) and $4.6^{\circ} \mathrm{C}$ for the year and $6.0^{\circ} \mathrm{C}$ for winter (RCP8.5), respectively. Minima are expected to increase even more, again mainly in winter $\left(4.5^{\circ} \mathrm{C}\right)$ and then in spring $\left(3.5^{\circ} \mathrm{C}\right)$ for RCP4.5 and by $8.3^{\circ} \mathrm{C}$ (winter) and $8.3^{\circ} \mathrm{C}$ (spring) for RCP8.5. The minima increase in annual values is similar to those of winter.

Precipitation sums are distinguished by high spatial and temporal variability. This is determined mainly by atmospheric circulation; the amount of precipitation depends on the type of synoptic situation. The complex orography of the Czech Republic has a significant influence as well. Long-term changes in rainfall are not detected. The annual variability is stronger than the trend.

Projection of the precipitation sums based on all 11 experiments shows a slight increase of about $7-13 \%$ for RCP4.5 and $6-16 \%$ for RCP8.5. Higher amounts of precipitation are observed by the end of the 21st century (Fig. S3 in the Supplement). A statistically significant trend $(8.3 \mathrm{~mm}$ per $10 \mathrm{yr}, \mathrm{p}=$ 0.05 ) is found for RCP4.5 for the period 2061-2100. The RCP8.5 emissions scenarios give a statistically significant trend of $16 \mathrm{~mm}$ per $10 \mathrm{yr}$ in the period 2021-2060 and $13 \mathrm{~mm}$ per $10 \mathrm{yr}$ in 2061-2100. RCP2.6 supposes an increase in precipitation only in the first period, 2021-2060 (14.7 mm per $10 \mathrm{yr}$ ). The biggest difference is observed for winter precipitation, where the increase could be up by $35 \%$ by the end of the 21st century (Table 6). In con- 
Table 5. Difference in air temperature $\left({ }^{\circ} \mathrm{C}\right)$ calculated from 11 experiments for individual periods and seasons (DJF: winter, MAM: spring, JJA: summer, SON: autumn) compared with reference period 1981-2010

\begin{tabular}{|lcccccc|}
\hline \multirow{2}{*}{ Emissions scenario } & Period & Year & DJF & MAM & JJA & SON \\
\hline RCP4.5 & $2021-2040$ & 0.9 & 1.1 & 0.8 & 0.7 & 0.8 \\
& $2041-2060$ & 1.3 & 1.4 & 1.3 & 1.3 & 1.1 \\
& $2061-2080$ & 1.8 & 2.2 & 1.8 & 1.7 & 1.5 \\
& $2081-2100$ & 2.0 & 2.4 & 1.9 & 1.7 & 1.7 \\
RCP8.5 & $2021-2040$ & 1.0 & 1.1 & 1.1 & 0.9 & 0.9 \\
& $2041-2060$ & 1.8 & 2.1 & 1.8 & 1.6 & 1.8 \\
& $2061-2080$ & 2.8 & 3.3 & 2.8 & 2.6 & 2.6 \\
& $2081-2100$ & 4.1 & 4.9 & 3.8 & 3.8 & 3.9 \\
\hline
\end{tabular}

Table 6. Ratio of precipitation sums calculated from 11 experiments for individual periods and seasons (DJF: winter, MAM: spring, JJA: summer, SON: autumn) compared with reference period 1981-2010 (100\%)

\begin{tabular}{|lcccccc|}
\hline Emissions scenario & Period & Year & DJF & MAM & JJA & SON \\
\hline RCP4.5 & $2021-2040$ & 106.6 & 109.3 & 105.9 & 105.0 & 107.4 \\
& $2041-2060$ & 107.0 & 110.5 & 111.5 & 100.9 & 108.7 \\
& $2061-2080$ & 110.3 & 115.9 & 115.1 & 104.4 & 109.5 \\
& $2081-2100$ & 112.7 & 114.0 & 119.3 & 107.5 & 112.4 \\
RCP8.5 & $2021-2040$ & 106.5 & 110.6 & 109.3 & 103.4 & 106.2 \\
& $2041-2060$ & 112.2 & 120.4 & 115.4 & 105.8 & 112.3 \\
& $2061-2080$ & 113.7 & 126.1 & 118.7 & 104.3 & 113.8 \\
& $2081-2100$ & 116.3 & 135.1 & 123.5 & 102.4 & 115.9 \\
\hline
\end{tabular}

or higher than 1, 10, 20 and $50 \mathrm{~mm}$. No statistically significant trends (for $\mathrm{p}=$ 0.05 ) are observed for the number of days with $1 \mathrm{~mm}$ and higher, but for 10, 20 or $50 \mathrm{~mm}$, positive statistically significant $(\mathrm{p}$ $=0.05$ ) linear trends were found. The increase of these intense rainfalls is mainly predicted by emissions scenario RCP8.5. For example, the number of days above $10 \mathrm{~mm}$ will increase in RCP8.5 by about $0.6 \mathrm{~d}$ per $10 \mathrm{yr}$ in the period 2021-2060 and by about $0.5 \mathrm{~d}$ per $10 \mathrm{yr}$ in 2061-2100. As can be seen in Table 7, the differences between the individual models are not so large. In the future, there will be about 1 additional day of intense rainfall of $\geq 20 \mathrm{~mm}$ compared to the present.

\subsection{Drought in the future}

Drought is becoming a very important phenomenon in our region, as it has been more and more frequent in recent years (drought occurred in the Czech Republic in 2012, 2013, 2014 and 2015). The reason for the droughts in the Czech Republic is

trast, the smallest change can be expected in summer precipitation.

As can be seen in Fig. S5 (in the Supplement), the changes in the precipitation sums are not spatially consistent. Again using the example of the Had GEM2-ES_RCA experiment, it is shown that the smallest increase should occur in South Moravia, which is among the most important agricultural regions. The differences between the periods and the emissions scenarios are large. Quite a large difference can be observed between the periods 20412060 (RCP4.5) and 2061-2080 (RCP8.5). In the first case, similar precipitation sums as for the present are predicted, but with the latter case, significantly higher precipitation sums of $>20 \%$ are modeled.

During the last decade (in the current climate in the Czech Republic), we have observed a change in precipitation patterns but with no similar change in the average. To capture such behavior, other precipitation characteristics also need to be investigated. We analyzed the number of days with precipitation equal below-normal amounts of precipitation and/or very high temperatures. The new Euro-CORDEX experiments predict slightly higher sums of precipitation, but, in connection with increased air temperature and a change in the precipitation pattern (change in rain frequency), we can expect an increase in evapotranspiration; thus, conditions will likely favour drought more in the future (Zahradníček et al. 2015). The drought in 2015 was one of the worst in the last $20 \mathrm{yr}$, and can be considered an example of how such periods could look in the future. The drought in 2015 started inconspicuously and then quickly escalated dramatically due to the high temperatures during the summer months (a record number of tropical days). This caused a significant drought across the whole
Table 7 . Number of days with precipitation $>20 \mathrm{~mm}$ for 3 experiments

\begin{tabular}{|lccccc|}
\hline Period & RCP & $\begin{array}{c}\text { EC-EARTH_ } \\
\text { RACMO }\end{array}$ & $\begin{array}{c}\text { HadGEM2-ES_ } \\
\text { RCA }\end{array}$ & $\begin{array}{c}\text { MPI-ESM-LR_- } \\
\text { CCLM }\end{array}$ & $\begin{array}{c}\text { Czech } \\
\text { Republic }\end{array}$ \\
\hline $1981-2010$ & & & & & 4.6 \\
$2021-2040$ & RCP4.5 & 4.7 & 5.2 & 5.5 & \\
& RCP8.5 & 4.5 & 5.4 & 5.0 & \\
$2081-2100$ & RCP4.5 & 5.3 & 5.8 & 5.7 & \\
& RCP8.5 & 6.2 & 5.9 & 5.9 & \\
\hline
\end{tabular}


country. It is for this reason we focus mainly on temperature extremes in this section.

Several consecutive days with high temperatures cause heat waves, which have the potential to deepen the drought. As a threshold for defining a heat wave for our analysis, we used $3 \mathrm{~d}$ with temperatures above $30^{\circ} \mathrm{C}$. The results are presented in the example of the 3 experiment outputs (Table $\mathrm{S} 1$ in the Supplement). In the 1981-2010 period, $3.7 \mathrm{~d} \mathrm{yr}^{-1}$ with heat waves occurred. No significant difference between RCP4.5 and RCP8.5 is predicted for the near future. The ECEARTH_RACMO experiment gives an even higher number of days in heat waves for RCP4.5. In any case, the number of days nearly doubles. The large increase in the number of such days and also the increase in the difference between both emissions scenarios occur during the last period of 2081-2100. Compared to the other 2 experiments, HadGEM2ES_RCA models a significantly higher number of days in heat waves. This experiment predicts $1 \mathrm{mo}(33 \mathrm{~d})$ in heat waves for emissions scenario RCP8.5, which is 10 times more than in the baseline period.

A tropical day occurs when the maximum air temperature reaches or exceeds the limit of $30^{\circ} \mathrm{C}$. The number of tropical days occurs only a few times a year, but, in the last 2 decades, the number has significantly increased. Such days can be described as uncomfortable for both people and nature. It causes an increase in evapotranspiration and quicker drying of the landscape. If we compare the number of tropical days in the 1960s with the beginning of the 21st century, it is occurring almost twice as often. The number of tropical days has increased mainly in the Moravian lowlands and lowlands around the river Elbe, which are places of importance for agricultural activity (Rožnovský \& Zahradníček 2014).

In the first future period (2021-2040), we do not observe a significant increase in the number of tropical days. The values correspond with those in the 2000s and 2010s. Greater variance in the projections between the models and even different emissions scenarios is observed for the end of the century. Emissions scenario RCP4.5 predicts twice the number of tropical days than observed in the period 1981-2010. The EC-EARTH_RACMO experiment predicts about $20 \%$ fewer tropical days than the other 2 models (Table S2 in the Supplement). Big differences are modeled by RCP8.5 (Fig. 6). Model HadGEM2-ES_RCA calculated about $50 \%$ higher number of tropical days than the other studied experiments. Such a significant increase in these hot days may cause major problems, not only in terms of drought, but also in the population's health, the energy sector, etc. Interestingly, in 2015, we measured 35-40 tropical days in the Czech Republic, which was higher than the projections of most models for the end of the 21st century.

\section{DISCUSSION AND COMPARISON WITH PREVIOUS RCM RESULTS}

As mentioned in the Introduction and Section 2.3, the models suffer from biases. Given our knowledge about physical processes in the atmosphere, computational possibilities, etc., results within the same group of models usually have similar problems. Kotlarski et al. (2014) summarizes some of these biases evaluated from the ERA-Interim-driven (Dee et al. 2011) Euro-CORDEX RCMs. They point to a predominant cold and wet bias in most seasons and over most parts of Europe and a warm and dry summer bias over southern and southeastern Europe. The other well-known issue with RCMs is, for instance, systematic underestimation of the dry-day frequency and, on the other hand, overestimation of light (between 0.1 and $1 \mathrm{~mm} \mathrm{~d}^{-1}$ ) and heavy precipitation frequency (Themessl et al. 2012). As has been shown in Section 3, we confirm similar bias patterns in our results for the Czech Republic.

In Section 3.2, we presented results based on biascorrected results and spatial aggregation over all available grid-points. To answer a possible question about the role of location density in the estimation of such an areal average for the Czech Republic, we analyzed averaging based on several versions of input datasets. The datasets are: the simple average of the values of 523 grid points of Euro-CORDEX simulations, and averages over 268 (air temperature) in respect to 787 (precipitation) station locations. We compared several characteristics for a $30 \mathrm{yr}$ period (1981-2010): air temperature, number of tropical days, precipitation sum and number of days with precipitation $\geq 1 \mathrm{~mm}$. As a reference dataset, we used an areal average based on a $500 \mathrm{~m}$ resolution grid layer obtained through geostatistical interpolation, namely, regression kriging applying the dependence of input station data (268 for temperature, 787 for precipitation) on altitude, longitude, slope, exposition and roughness. When comparing the results from these 4 data sources, they are practically the same, with the differences being a maximum of $0.1^{\circ} \mathrm{C}$ for air temperature and $4 \%$ in the case of precipitation or number of days. To conclude, the density of the Euro-CORDEX grid points does not have much effect on the results; it is comparable with other ver- 


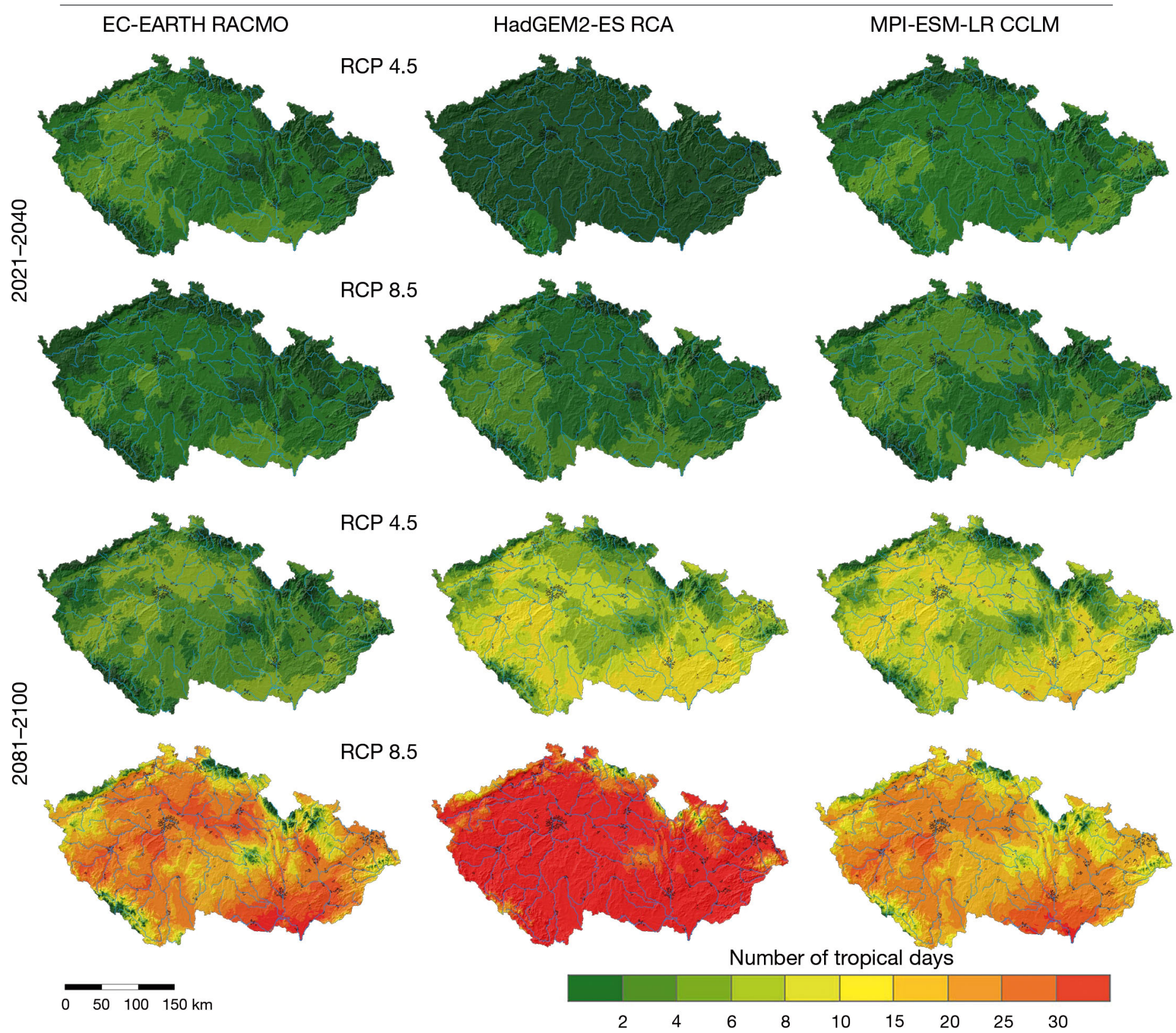

Fig. 6. Spatial differences in number of tropical days between future periods (2021-2040 and 2081-2100) and the present (1981-2010), for 3 experiments (EC-EARTH_RACMO, HadGEM2-ES_RCA, and MPI-ESM-LR_CCLM), and 2 scenarios

(RCP4.5 and RCP8.5) across the Czech Republic

sions of national mean average with a different number of points used for the calculation.

The previous studies of future climate in the Czech Republic were mostly based on 3 simulations of 2 RCMs: ALADIN-Climate/CZ in $10 \mathrm{~km}$ and $25 \mathrm{~km}$ resolutions (ALADIN-10 and ALADIN-25), and RegCM3 in $10 \mathrm{~km}$ resolution (RegCM-10). Since these results are still widely used (at least within the Czech Republic), we decided to discuss the differences between the new findings presented in Section 3 of the present paper and the previous studies. Both simulations at $10 \mathrm{~km}$ resolution (ALADIN-10 and RegCM-10) were originally prepared within EU FP6
CECILIA (www.cecilia-eu.org/), covered 2 future periods, 2021-2050 and 2071-2100, and followed the path of greenhouse gas emissions according to the IPCC A1B (SRES) emissions scenario. The same emissions scenario was also chosen for the ALADIN$25 \mathrm{~km}$ transient simulation, covering the period 1961-2100. The ALADIN-Climate/CZ simulations were directly driven by the stretched version of the ARPEGE GCM. The GCM stretching technique increases the resolution of a GCM over a selected region (to $\mathrm{ca} .50 \mathrm{~km}$ in the case of ARPEGE) and reduces it on the opposite side of the globe. Thus, GCM stretching reduces the jump in spatial resolu- 
tion between the driving GCM and the downscaling RCM. In the case of the RegCM-10 experiment, a double nesting from ECHAM GCM via $25 \mathrm{~km}$ RegCM3 simulation was used. According to all 3 experiments, air temperature will climb in the future. In the near future, 2021-2050, air temperature in the Czech Republic will rise by about $1.2-1.5^{\circ} \mathrm{C}$. This increase is within the range of warming calculated for the RCP4.5 and RCP8.5 emissions scenarios from the Euro-CORDEX models. For the periods 2021-2041 and 2041-2061, the Euro-CORDEX models expect a warming of $0.9-1.3^{\circ} \mathrm{C}$ for RCP4.5 and $1.0-1.8^{\circ} \mathrm{C}$ for RCP8.5. For the last $30 \mathrm{yr}$ of the 21st century (20712100), older experiments (with the A1B scenario) indicated an air temperature rise of $3.2-3.3^{\circ} \mathrm{C}$. This temperature change is close to what simulations based on the RCP8.5 scenario expect $\left(2.8-4.1^{\circ} \mathrm{C}\right)$. RCP4.5-based simulations envisage rather milder warming $\left(1.8-2.0^{\circ} \mathrm{C}\right)$. The older and newer generations of RCM experiments differ in seasonal temperature change. A slightly higher increase in the temperature is predicted in winter and summer by ALADIN-10 in the period 2021-2050. In contrast, RegCM-10 calculated the change in temperatures during the summer to be significantly smaller than in other seasons. The ALADIN-25 model gives a relatively similar increase for all seasons; the only lower trend is predicted for spring. Both models based on ALADIN-Climate/CZ calculated a higher increase in the temperatures in summer for the distant future (2071-2100). In contrast, RegCM-10 predicts a higher increase in the winter temperature for the period 2071-2100. For both emissions scenarios, the climate models based on Euro-CORDEX calculated a higher growth rate in air temperatures in the winter season for both the near and distant future. The changes in the seasons' air temperatures calculated by Euro-CORDEX are probably closest to the projections of the former RegCM-10 model.

Further, previous experiments calculated a slightly higher annual amount of precipitation on average for the whole Czech Republic for the period 2021-2050. The increase in rainfall was modeled between 4 and $7 \%$. This is relatively consistent with the new results, which predict an increase in annual precipitation of between 7 and $12 \%$. Differences are observed in the projections for seasonal changes. A significant decrease in winter precipitation was indicated by the ALADIN-10 and ALADIN-25 experiments. The decrease in winter precipitation was about $15 \%$. Similar phenomena occurred in the present climate, with the last 5 winters having a lower amount of precipitation and snow. A decrease in winter precipitation is not modeled by RegCM-10, however. The new results of the Euro-CORDEX experiments do not show a decrease in winter precipitation; on the contrary, they indicate an amount higher by about 9-20\%. Previous experiments expected an increase of about $20 \%$ in autumn precipitation and about $10 \%$ for summer. Conversely, the new results show only a slight increase in summer precipitation, which could be very dangerous in connection with the higher temperature (significantly higher evaporation). Autumn precipitation is predicted by the new models to be higher by only about $7-12 \%$, which is lower than the assumption of previous experiments. The differences between the previous and current versions of the climate models are pronounced in the case of precipitation in the distant future (2071-2100). ALADIN-10 and ALADIN-25 predicted slight decreases in annual precipitation $(2-3 \%)$. Conversely, new models in accordance with older model outputs RegCM-10 gives annual precipitation increasing by about 10-16\%. The ALADIN-Climate/CZ model (ALADIN-10, ALADIN-25), unlike during the first period, did not predict such decline in winter precipitation $(4 \%)$, while there is a visible modeled decline in summer precipitation (10-12\%). The RegCM-10 models an increase in winter, autumn and spring rainfall of up to $20 \%$, but does not predict any significant change in summer precipitation. The outputs of the new experiments predict an ongoing increase in winter precipitation in the distant future, as opposed to the older model outputs by ALADINClimate/CZ. Winter precipitation is modeled to be higher by an amount of about $26-35 \%$, especially for emissions scenario RCP8.5. A decline in summer precipitation is not observed in the new model outputs.

\section{CONCLUSIONS}

In the case of the original (uncorrected) model outputs, the differences between the individual models are large. After bias correction, the absolute values for future climate became more stable and suitable for ongoing analysis within impact studies.

All 11 available Euro-CORDEX experiments were bias-corrected. Most experiments underestimated temperature by up to $2.5^{\circ} \mathrm{C}$. Conversely, the increase in air temperature is greater than in reality (for the control run). The found biases are not spatially identical; they vary significantly with altitude. The precipitation sums are overestimated by uncorrected experiments by up to $0.65 \mathrm{~mm} \mathrm{~d}^{-1}$, but the differences between models are large. The spatial differences of the model biases are not the same for all the 
experiments, and their analysis by altitude level does not show clear results. Uncorrected RCM outputs would be useless for an impact study of a regional character, since uncorrected RCMs do not capture the conditions for the Czech Republic well.

Air temperature will increase similarly up to 2050 irrespective of the emissions scenario. Temperature will be higher by about $1^{\circ} \mathrm{C}$ in the period 2021-2040 compared to 1981-2010. After the year 2050, we observe growing differences between the emissions scenarios. For the whole Czech Republic, based on all 11 available experiments, air temperature will increase by $2.0^{\circ} \mathrm{C}(\mathrm{RCP} 4.5)$ to $4.1^{\circ} \mathrm{C}(\mathrm{RCP} 8.5)$ for the whole year and for the end of the 21st century compared to the reference period (1981-2010). In contrast, RCP2.6 predicts the halting of growth in air temperature by 2060 , and even indicates a slow decline. Looking at individual seasons, the highest increase in temperature is modeled in winter. The projections for precipitation gives a slight increase of about $7 \%$ (2021-2040) to $13 \%$ (the end of the $21 \mathrm{st}$ century) for RCP 4.5 , and $6 \%$ to $16 \%$ for RCP8.5. The changes are mostly statistically significant $(p=0.05)$. A stronger trend can be found in the outputs for emissions scenario RCP8.5. The biggest difference is observed in winter precipitation, which could end up with an increase of $35 \%$ by the end of the 21 st century, whereas the smallest change can be expected in summer precipitation.

Climate change is also reflected in the climatic indices. The experiments predict an increase in the number of tropical days, which is also manifested in the growing number of heat waves. Alarming results by the end of the 21st century are predicated mainly with emissions scenario RCP8.5. These results are not unrealistic, as a similar number of tropical days as predicted by RCP8.5 for the period of 2081-2100 occurred in the year 2015 in the Czech Republic. Higher temperatures can lead to more intense rains from thunderstorms. Significant trends were found in the number of days with precipitation of 10, 20 and $50 \mathrm{~mm}$ and higher.

Considering the simulated changes in air temperature and changes in the precipitation regime for the future, we can expect more frequent and severe drought occurrences. In this article, the conclusions are based solely on the climate variables that induce drought, but special drought indices were calculated as well, and we will follow up with articles devoted to their analysis.

Acknowledgements. This work was supported by the Ministry of Education, Youth and Sports of the Czech Republic within the National Sustainability Program I (NPU I), grant no. LO1415. We further acknowledge these projects: P.Š.: project no. LD14043 'Validation and correction of RCMs outputs in the area of the Czech Republic for purposes of impact studies' (Ministry of Education, Youth and Sports, Czech Republic); and project no. 14-12262S (Czech Science Foundation). P.Z. was supported by the project 'Hydrometeorological extremes in Southern Moravia derived from documentary evidence' (Czech Science Foundation, no. 13-19831S), and M.T. was supported by project no. 16-16549S 'Soil moisture and run-off droughts in future climate'.

\section{LITERATURE CITED}

Brázdil R, Trnka M (eds) (2015) Sucho v českých zemích: minulost, současnost, budoucnost (Drought in the Czech Lands: past, present, future). Centrum výzkumu globální změny Akademie věd České republiky, v.v.i., Brno

> Brázdil R, Trnka M, Mikšovský J, Rezníčková L, Dobrovolný $\mathrm{P}$ (2015) Spring-summer droughts in the Czech Land in 1805-2012 and their forcings. Int $\mathrm{J}$ Climatol 35: $1405-1421$

Brázdil R, Raška P, Trnka M, Zahradníček P and others (2016) The disastrous drought of 1947 in the Czech Lands: its course, trigger-factors, impacts and consequences. Clim Res 70:161-178

Christensen JH, Christensen OB (2007) A summary of the PRUDENCE model projections of changes in European climate by the end of this century. Clim Change 81:7-30

Christensen $\mathrm{JH}$, Boberg F, Christensen OB, Lucas-Picher P (2008) On the need for bias correction of regional climate change projections of temperature and precipitation. Geophys Res Lett 35:L20709

Clarke L, Edmonds J, Jacoby H, Pitcher H, Reilly J, Richels $\mathrm{R}$ (2007) Scenarios of greenhouse gas emissions and atmospheric concentrations. Sub-report 2.1A of Synthesis and Assessment Product 2.1 by the US Climate Change Science Program and the Subcommittee on Global Change Research. Office of Biological and Environmental Research, US Department of Energy, Washington, DC

> Dee DP, Uppala SM, Simmons AJ, Berrisford P and others (2011) The ERA-Interim reanalysis: configuration and performance of the data assimilation system. QJR Meteorol Soc 137:553-597

> Déqué M (2007) Frequency of precipitation and temperature extremes over France in an anthropogenic scenario: model results and statistical correction according to observed values. Global Planet Change 57:16-26

> Farda A, Déqué M, Somot S, Horányi A, Spiridonov V, Tóth H (2010) Model ALADIN as regional climate model for Central and Eastern Europe. Stud Geophys Geod 54: 313-332

Frei C, Christensen JH, Déqué M, Jacob D, Jones RG, Vidale PL (2003) Daily precipitation statistics in regional climate models: evaluation and intercomparison for the European Alps. J Geophys Res Atmos 108:4124

Giorgi F, Mearns LO (1991) Approaches to the simulation of regional climate change: a review. Rev Geophys 29: 191-216

Giorgi F, Mearns LO (1999) Introduction to special section: regional climate modelling revisited. J Geophys Res Atmos 104:6335-6352

Giorgi F, Jones C, Asrar G (2009) Addressing climate infor- 
mation needs at the regional level: the CORDEX framework. WMO Bull 58:175-183

Goodess CM, Aganostopoulou C, Bárdossy A, Frei C (2012) An intercomparison of statistical downscaling methods for Europe and European regions - assessing their performance with respect to extreme temperature and precipitation events and the implications for climate change applications. Tech Rep Climatic Research Unit, Norwich

Gutjahr O, Heinemann G (2013) Comparing precipitation bias correction methods for high-resolution regional climate simulations using COSMO-CLM: effects on extreme values and climate change signal. Theor Appl Climatol 114:511-529

Hanel M, Vizina A, Maca P, Pavlasek J (2012) A multi-model assessment of climate change impact on hydrological regime in the Czech Republic. J Hydrol Hydromech 60: 152-161

> Hanel M, Mrkvičkova M, Maca P, Vizina A, Pech P (2013) Evaluation of simple statistical downscaling methods for monthly regional climate model simulations with respect to the estimated changes in runoff in the Czech Republic. Water Resour Manage 27:5261-5279

- Hlavinka P, Trnka M, Semerádová D, Dubrovský M, Žalud Z, Možný M (2009) Effect of drought on yield variability of key crops in Czech Republic. Agric For Meteorol 149: 431-442

Kingston DG, Stagge JH, Tallaksen LM, Hannah DM (2015) European-scale drought: understanding connections between atmospheric circulation and meteorological drought indices. J Clim 28:505-516

Kotlarski S, Keuler K, Christensen OB, Colette A and others (2014) Regional climate modeling on European scales: a joint standard evaluation of the EURO-CORDEX RCM ensemble. Geosci Model Dev 7:1297-1333

Maraun D (2013) Bias correction, quantile mapping and downscaling: revisiting the inflation issue. J Clim 26: 2137-2143

> Maraun D, Wetterhall F, Ireson AM, Chandler RE and others (2010) Precipitation downscaling under climate change: recent developments to bridge the gap between dynamical models and the end user. Rev Geophys 48:RG3003

Mearns L, Arritt R, Biner S, Bukovsky MS and others (2012) The North American Regional Climate Change Assessment Program: overview of Phase I results. Bull Am Meteorol Soc 93:1337-1362

- Meinshausen M, Smith SJ, Calvin K, Daniel JS and others (2011) The RCP greenhouse gas concentrations and their extensions from 1765 to 2300. Clim Change 109: 213-241

Moss R, Babiker M, Brinkman S, Calvo E and others (2008) Towards new scenarios for analysis of emissions, climate change, impacts, and response strategies. IPCC, Geneva

Pal JS, Giorgi F, Bi X, Elguindi N and others (2007) Regional climate modeling for the developing world: the ICTP RegCM3 and Reg-CNET. Bull Am Meteorol Soc 88: 1395-1409

Räty O, Räisänen J, Ylhäisi J (2014) Evaluation of delta change and bias correction methods for future daily precipitation: intermodel cross-validation using ENSEMBLES simulations. Clim Dyn 42:2287-2303

Riahi K, Gruebler A, Nakicenovic N (2007) Scenarios of long-term socio-economic and environmental development under climate stabilization. Technol Forecast Soc Change 74:887-935

Rožnovský J, Zahradníček P (2014) Air temperatures and conditions for recreation. In: Fialová J, Pernicová D (eds) Public recreation and landscape protection - with man hand in hand. Křtiny, 5-6 May 2014, p 27-31

Spinoni J, Naumann G, Vogt J, Barbosa P (2016). Meteorological droughts in Europe: events and impacts-past trends and future projections. Publications Office of the European Union, Luxembourg, EUR 27748 EN, doi:10. 2788/450449

Štěpánek P (2008) AnClim — software for time series analysis. Department of Geography, Faculty of Natural Sciences, Masaryk University, Brno. www.climahom.eu/An Clim.html

Štěpánek P (2010) ProClimDB - software for processing climatological datasets. Czech Hydrometeorological Institute, regional office, Brno. www.climahom.eu/ProcData. html

S Štěpánek P, Zahradníček P, Skalák P (2009) Data quality control and homogenization of air temperature and precipitation series in the area of the Czech Republic in the period 1961-2007. Adv Sci Res 3:23-26

Štěpánek P, Zahradníček P, Huth R (2011) Interpolation techniques used for data quality control and calculation of technical series: an example of Central European daily time series. Id járás 115:87-98

Štěpánek P, Skalák P, Farda A, Zahradníček P (2012) Climate change in the area of the Czech Republic according to various model simulations. In: Kožnarová V, Sulovská S, Hájková L (eds) Proc BIOCLIMATE 2012 - Bioclimatology of Ecosystems, 29-31 August 2012, Ústi nad Labem, Prague

Štěpánek P, Zahradníček P, Farda A (2013) Experiences with data quality control and homogenization of daily records of various meteorological elements in the Czech Republic in the period 1961-2010. Id járás 117:123-141

Stocker TF, Qin D, Plattner GK, Tignor M and others (eds) (2013) Climate change 2013: the physical science basis. Working Group I contribution to the Fifth Assessment Report of the Intergovernmental Panel on Climate Change. Cambridge University Press, Cambridge

Suklitsch M, Gobiet A, Truhetz H, Awan NK, Göttel H, Jacob D (2010) Error characteristics of high resolution regional climate models over the Alpine area. Clim Dyn 37:377-390

Taylor KE, Stouffer RJ, Meehl GA (2012) An overview of CMIP5 and the experiment design. Bull Am Meteorol Soc 93:485-498

Teutschbein C, Seibert J (2013) Is bias correction of regional climate model (RCM) simulations possible for non-stationary conditions? Hydrol Earth Syst Sci 17:5061-5077

Themessl MJ, Gobiet A, Leuprecht A (2011) Empiricalstatistical downscaling and error correction of daily precipitation from regional climate models. Int J Climatol 31: 1531-1544

Themessl MJ, Gobiet A, Heinrich G (2012) Empirical-statistical downscaling and error correction of regional climate models and its impact on the climate change signal. Clim Change 112:449-468

Trnka M, Kysely J, Možny M, Dubrovsky M (2009) Changes in Central-European soil-moisture availability and circulation patterns in 1881-2005. Int J Climatol 29:655-672

- Trnka M, Brázdil R, Možný M, Štěpánek P and others (2015) Soil moisture trends in the Czech Republic between 1961 and 2012. Int J Climatol 35:3733-3747

UNISDR (United Nations Secretariat of the International Strategy for Disaster Reduction) (2009) Drought risk 
reduction framework and practices. Contributing to the implementation of the Hyogo Framework for Action. UNISDR, Geneva

van der Linden P, Mitchell JFB (2009) ENSEMBLES: climate change and its impacts: summary of research and results from the ENSEMBLES project. Tech Rep. Met Office Hadley Centre, Exeter

van Vuuren DP, den Elzen MGJ, Lucas PL, Eickhout B and others (2007) Stabilizing greenhouse gas concentrations at low levels: an assessment of reduction strategies and costs. Clim Change 81:119-159

Editorial responsibility: Michael Hayes (Guest Editor), Lincoln, Nebraska, USA van Vuuren DP, Edmonds J, Kainuma M, Riahi K and others (2011) The representative concentration pathways: an overview. Clim Change 109:5-31

Wang Y, Leung LR, McGregor JL, Lee DK, Wang WC, Ding Y, Kimura F (2004) Regional climate modeling: progress, challenges, and prospects. J Meteorol Soc Jpn 82: 1599-1628

Zahradníček P, Trnka M, Brázdil R, Možný M and others (2015) The extreme drought episode of August 2011/ May 2012 in the Czech Republic. Int J Climatol 35: 3335-3352

Submitted: April 4, 2016; Accepted: August 16, 2016 Proofs received from author(s): October 19, 2016 